\title{
Calibration setup with metrological support for space qualified electric field probe
}

\author{
Alexey Kozlov ${ }^{1, *}$, Alexander Shilov ${ }^{1}$, Alexey Styuf ${ }^{1}$, Alexander Doroshkin ${ }^{1}$, \\ and Anatoly Nikitenko ${ }^{1,2}$ \\ ${ }^{1}$ Novosibirsk State University, 630090 Novosibirsk, Russia \\ ${ }^{2}$ Siberian State University of Water Transport, 630099 Novosibirsk, Russia
}

\begin{abstract}
The article shows the results of calculations necessary for testing to approve the space qualified electric field probe used in outer space. A special electric field probe calibration setup was developed and manufactured, which allows testing a space qualified electric field probe in the entire measurement range (from \pm 0.1 to $\pm 200 \mathrm{kV} / \mathrm{m}$ ) under low ( -80 $\left.{ }^{\circ} \mathrm{C}\right)$ and high $\left(+72{ }^{\circ} \mathrm{C}\right)$ temperatures and at reduced pressure of $1.3 \cdot 10^{-3} \mathrm{~Pa}$ $\left(10^{-5}\right.$ torr). Metrological tests of the probes batch, calibrated by the space qualified electric field probe calibrator, performed at the verification equipment under normal conditions, showed that the maximum error of the electric field probe does not exceed $15 \%$ in the entire measurements range which will increase the accuracy of determining the satellite surface charging parameters and help in designing modern spacecrafts.
\end{abstract}

\section{Introduction}

Charging the satellite surface due to low-energy particles flows has been studied since the early 1970s [1] and up to the present [2-4]. This phenomenon plays an important role for satellites located in highly elliptical and polar orbits, where the intersection with the Earth's radiation belts is regular [5]. The spacecraft passing through the magnetosphere with a high concentration of charged particles leads to the charge accumulation on the dielectric surfaces and induce surface electrostatic discharges, which have a destabilizing effect on the onboard equipment. Therefore, it is important to monitor the charge levels on the spacecraft surfaces.

Also, this problem is actual for small spacecrafts $[6,7]$, in particular, of the CubeSat type [8], since a significant part of such satellites locate in solar-synchronous and polar orbits, with a frequent crossing of the Earth's radiation belts. Today the massive use of nanosatellites for educational purposes stimulates the development of scientific programs using small spacecrafts, and a lot of commercial programs have been launched in this connection. In these conditions, the spacecraft resource becomes important, and this means that destabilizing factors and, in particular, the spacecraft surface charging should be controlled.

\footnotetext{
* Corresponding author: Alexey.koslov@yandex.ru
} 
The desire to expand the functionality of small spacecrafts stimulates the use of different jet propulsion devices. When accelerated charged particles are the basis of such an engine $[9,10]$, charge accumulation can take place and, if it is not compensated under control, the engine thrust goes to zero. Thus, monitoring the spacecraft charge level is also very important in this case.

Controlled charging of dielectric surfaces is also needed in laboratory studies of the materials charging by plasma direct impact [11, 12], as well as in microcircuits and materials radiation tests $[13,14]$.

Novosibirsk State University has developed several generations of diagnostic equipment [for example, 15, 16], covering the above-mentioned issues of surface charging control. To measure the spacecraft surface charge, the space qualified electric field probe is used [17, 18]. Probe's technical specifications: dimensions, mass, power consumption and temperature range, Figure 1, allow applying it in CubeSat satellites.
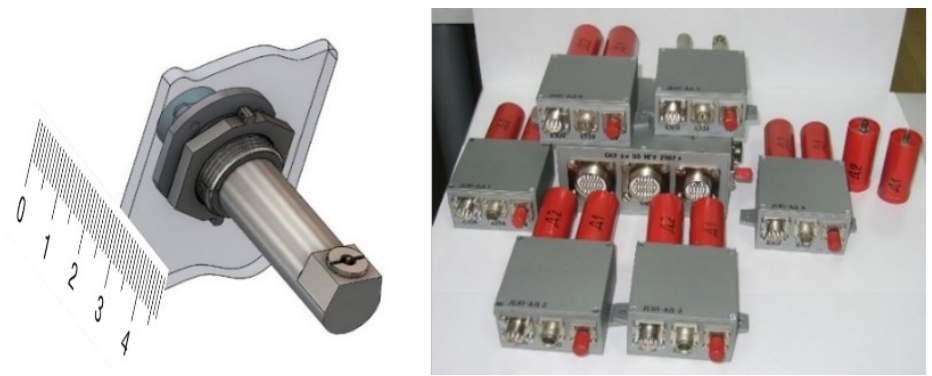

Fig. 1. Electric field probe (left) and surface charge control equipment (right).

A thorough study of surface charging processes requires to use measuring instruments with approved metrological characteristics. However, the existing secondary standards (for example, the verification equipment for measuring the electric field intensity P1-23 [19]) do not allow testing electric field probes in conditions close to the operation modes on the spacecraft. Due to the fact that the probe is designed taking into account operation in outer space, its operability, including metrological characteristics, should be approved throughout the temperature range and under reduced pressure. However, today it is possible to determine its metrological characteristics only in normal climatic conditions, since the Federal Information Fund for Ensuring the Uniformity of Measurements lacks the measuring standards necessary to determine the probe metrological characteristics under conditions identical to its operating conditions.

This article is devoted to the metrological certification of the standard, which will be used to approve the space qualified electric field probes in conditions close to the outer space environment.

\section{Calibrator description}

In order to solve this problem, the KDEP-200 electric field probe calibration setup was designed as a flat capacitor, which was adapted to be installed in a thermal chamber or thermovacuum chamber to test electric filed probes in the entire temperature range (from -80 to $+100{ }^{\circ} \mathrm{C}$ ) and at reduced pressure from $1.3 \cdot 10^{-4}$ to $1.3 \cdot 10^{-2} \mathrm{~Pa}$ (from $10^{-6}$ to $10^{-4}$ torr). The general view of the calibrator is shown in Fig. 2. 


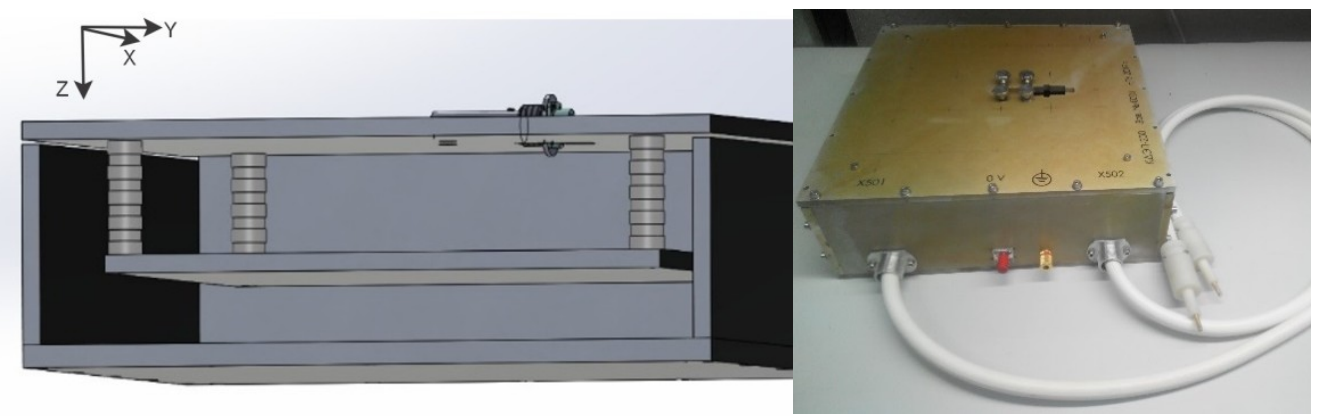

Fig. 2. KDEP-200 electric field probe calibrator (left); General view of KDEP-200 (right).

Based on the results of the finite elements method, it was found that the field strength in the probe measurement area differs from the field strength in the flat capacitor by no more than $0.16 \%$ (see Figure 3).
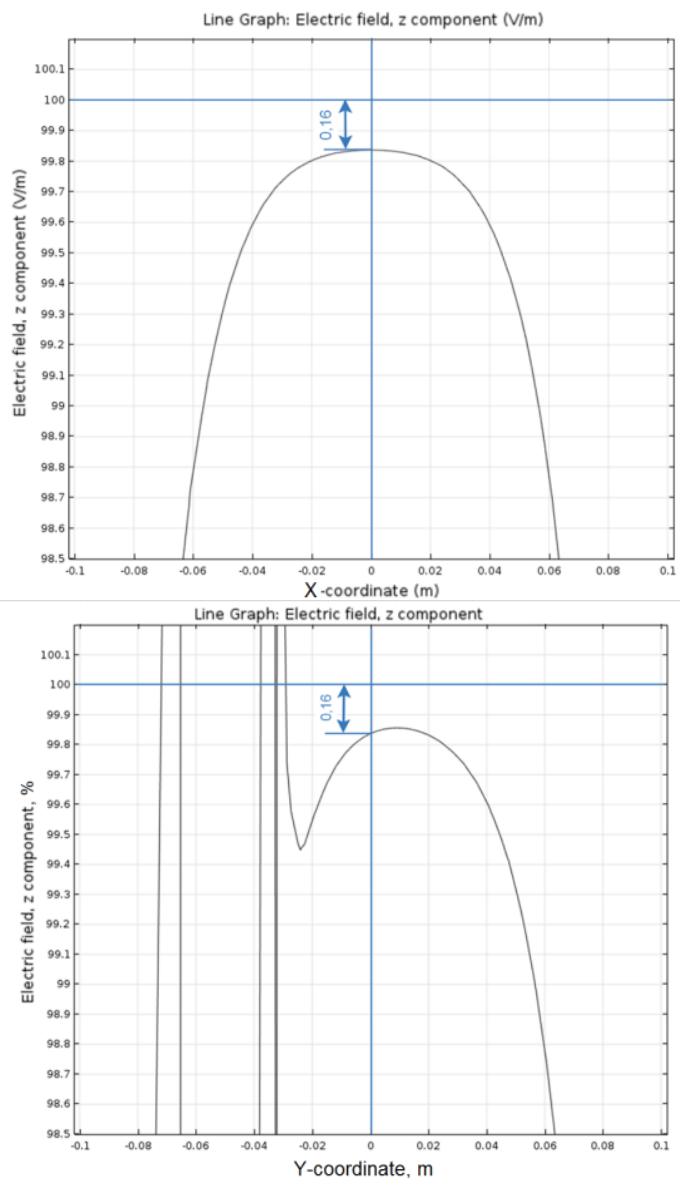

Fig. 3. Distribution of the Z-component of the electric field strength along the coordinate $X$ (left) and the coordinate $\mathrm{Y}$ (right).

The final error of the calibrator is also affected by the capacitor thermal linear expansion, change in the dielectric permittivity of the medium under various conditions of 
use, and metrological characteristics of additional measuring instruments (high voltage divider, voltmeter, slide caliper). The resulting relative extended measurement uncertainty at KDEP-200 with a confidence probability $\mathrm{P}=95 \%$ does not exceed $5 \%$, which corresponds to the maximum permissible standard accuracy intended for probes calibration having an accuracy of $15 \%$. Based on the results of the KDEP-200 certification performed in 2017 , the relative extended uncertainty of measurements on the standard was $2.28 \%$.

In order to compare the KDEP-200 calibrator with the secondary standard, similar to the state primary standard of the electric field strength unit, the first calibration of the qualified electric field probes batch was performed at KDEP-200. The tests of this batch under normal conditions at the P1-23 reference equipment showed that the maximum deviation of the field strength measured by the probe does not exceed $15 \%$ of the P1-23 readings (Figure 4), which meets the requirements for the electric field probes. Further tests in the entire temperature range, including tests under reduced pressure, and determination of the electric field probes metrological characteristics can also be performed.

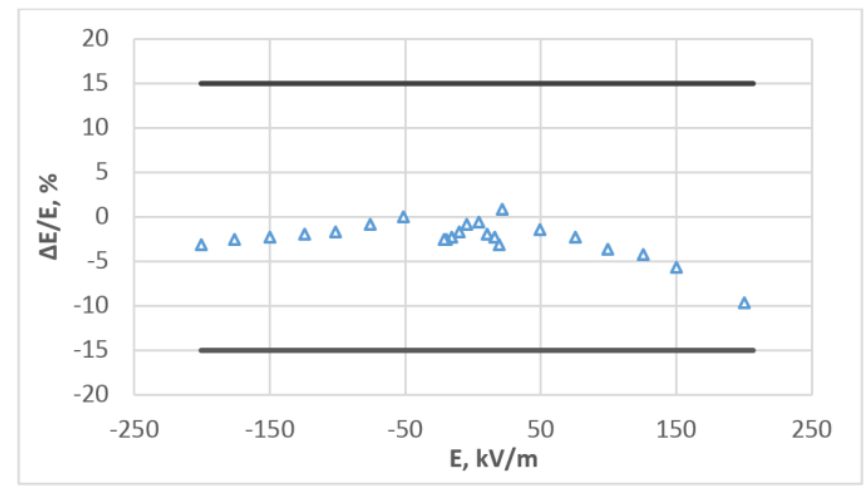

Fig. 4. Deviation of the calibrated by KDEP-200 electric field probe's readings from the P1-23 readings.

\section{Conclusion}

Thus, the developed KDEP-200 calibration setup meets the metrological requirements for standards and will be applied to calibrate the space qualified electric field probes. This will increase the accuracy of determining the spacecraft's surface charging parameters and can be used to improve charging models in modern spacecraft's design, including small CubeSat satellites. This achievement will allow controlling the charging destabilizing effect on onboard equipment, optimizing the operation of small engines based on accelerated charged particles, and providing reliable determining the material static characteristic in laboratory studies using plasma methods and radioactive tests.

This work was supported by the Ministry of Education and Science of the Russian Federation: Project No. 14.575.21.0154, Project Identification No. RFMEFI57517X0154.

\section{References}

1. S. E. DeForest, J. Geophys. Res., 77, Feb. 1, 65 (1972)

2. X. Meng, D Chen, L. Shi, S. Liu, S. Chen, IEEE Transactions on Plasma Science 45(8), 2013 (2017) 
3. I. Sillanpää, N.Y. Ganushkina, S. Dubyagin, J.V. Rodriguez, Space Weather 15 (12), 1602 (2017)

4. Y. Xiangqian, C. Hongfei, Z. Qiugang, W. Jianzhao, S. Weihong, Z. Hong, Z. Jiqing, Z. Weiying, C. Zhe, S. Sipei, J. Xianghong, IEEE Transactions on Nuclear Science 64(11), 2822 (2017)

5. V. V. Ivanov, I. A. Maksimov, N.N. Sitnikova, V. V. Khartov, Yu. M. Prokop'ev, Kosmonavtika i raketostroenie [Cosmonautics and rocket production] 1(30), 102 (2003)

6. D. Bock, P. Laufer, and M. Tajmar, 30 th International Vacuum Nanoelectronics Conference (IVNC), 1560 (2017)

7. R.M. Albarran, A. Barjatya,A. Journal of Spacecraft and Rockets 53(3), 393 (2016)

8. ISO 17770:2017(E) «Space systems -- Cube satellites (CubeSats)»

9. Fernando Mier-Hicks Thesis: Ph. D., Massachusetts Institute of Technology, Department of Aeronautics and Astronautics, 2017.

10. D. Bock, P. Laufer, M. Tajmar, 2017 30th International Vacuum Nanoelectronics Conference, IVNC 2017, 96 (2017)

11. A.A. Chirov, A.B. Nadiradze, V.V. Shaposhnikov Journal of Surface Investigation: XRay, Synchrotron and Neutron Techniques 8(4), 689 (2014)

12. K. Chou, and J. Wang, Review of Scientific Instruments 88, (2017).

13. E.I. Rau, A.A. Tatarintsev, E.Y. Zykova, Physics of the Solid State 59(8), 1526 (2017)

14. L. K. Sarno-Smith, B. A. Larsen, R. M. Skoug, M. W. Liemohn, A. Breneman, J. R. Wygant, and M. F. Thomsen, Space Weather 14(2), 151 (2016)

15. L. I. Aristov, M. S. Borodin, Y. M. Prokopiev, Scientific-technical development of KB "Salyut" for 2009-2011 3, 327 (2012)

16. A. Pelemeshko, A. Styuf, V. Prokopyev, Y. Prokopyev, A. Zadorozhny, MATEC Web of Conferences 102, 1 (2017)

17. Patent RU 2414717 A.M. Shilov, Ju. M. Prokop'ev, V. Ju. Prokop'ev, I.V. Shchepikhin, Priority of 18.01.2010. Registered with the Public Register for Inventions 20.03.2011, Bull. 8

18. A.S. Kozlov, A.M. Shilov, Y.M. Prokopiev, Proc. of V International Forum for Young Scientists «Space Engineering», 7 (2017).

19. The calibration setup for the measurement unit of electrostatic field P1-23. Available at http://www.ciklon-pribor.ru/?catname $=\%$ CF1-23 (accessed 31 January 2017) 